\title{
GAMBARAN PERAN PERAWAT DALAM PENCEGAHAN DEKUBITUS DI BANGSAL PENYAKIT DALAM RUMAH SAKIT DI YOGYAKARTA
}

\section{NURSES ROLE'S IN DECUBITUS PREVENTION IN INTERNAL MEDICINE WARD OF HOSPITAL IN YOGYAKARTA}

\author{
Muhamat Nofiyanto $^{1 *}$, Erna Ivana ${ }^{2}$ \\ ${ }^{* 1}$ Program Studi Keperawatan (S1) Fakultas Kesehatan Universitas Jenderal A. Yani Yogyakarta, \\ Jl. Brawijaya Ambarketawang Gamping Sleman, email:muhamatnur@gmail.com, Indonesia. \\ 2 Program Studi Keperawatan (S1) Fakultas Kesehatan Universitas Jenderal A. Yani Yogyakarta, \\ Jl. Brawijaya Ambarketawang Gamping Sleman, Indonesia.
}

\section{ABSTRACT}

Background : Decubitus prevention need the knowledge, attitude, motivation, and behavior of nurses.

Objective : To identify the description of nurses role's in decubitus prevention in Internal medicine ward of hospital in Yogya.

Method : This was a descriptive design by using cross sectional time approach. The number of samples was 15 respondents selected through total sampling technique. The analysis applied descriptive statistic.

Result : The majority of nurses had positive role's in decubitus prevention as many as 10 respondents $(66.7 \%)$, the nurses role's according to some characteristics were as follows; The nurses role in the assessment on decubitus risk factor was in good category as many as 9 respondents $(60.0 \%)$, the nurses role in skin care for patients was in good category as many as 9 respondents $(60.0 \%)$, the nurses role in patients nutritional status enhancement was in good category as many as 10 respondents (66.7\%), the nurses role in support surface was in sufficient category as many as 12 respondents $(80.0 \%)$, and the nurses role in providing education was in good category as many as 13 respondents $(86.7 \%)$.

Conclusion: The nurses role's in decubitus prevention in internal medicine ward of hospital in Yogya is in good category.

Keywords : Decubitus prevention, Nurses role's,Positive role's

\section{PENDAHULUAN}

Dekubitus merupakan masalah yang serius karena dapat mengakibatkan meningkatnya biaya, lama perawatan, dan memperlambat program rehabilitas pasien, dekubitus juga dapat menyebabkan nyeri berkepanjangan, rasa tidak nyaman, dan komplikasi berat yang mengarah ke sepsis, infeksi kronis, selulitis, osteomyelittis, dan meningkatkan prevalensi mortalitas pada klien lanjut usia. ${ }^{1}$ Insiden dekubitus di Study International sebanyak 1.9\%-63.6\%, ASEAN (Jepang, Korea, Cina) $2.1 \%-18 \%$, dan di Indonesia cukup tinggi yaitu 33.3\%. ${ }^{2}$ Survei yang dilakukan WHO terhadap 55 rumah sakit di 14 negara menunjukkan 8,7\% dari rumah sakit tersebut terdapat pasien dengan dekubitus dan 1,4 juta orang di seluruh dunia menderita luka dekubitus akibat perawatan di rumah sakit. ${ }^{3}$ Kejadian dekubitus secara umum dilaporkan bahwa $5-11 \%$ terjadi di tatanan perawatan acute care, $15-25 \%$ di tatanan perawat jangka panjang, dan $7-12 \%$ di tatanan perawatan rumah. ${ }^{4}$ Frekuensi luka dekubitus cukup tinggi terjadi pada pasienpasien neurologis karena immobilisasi yang lama dan berkurangnya kemampuan sensorik. $^{5}$ Upaya pencegahan dekubitus perlu memperhatikan pengetahuan, sikap, motivasi, dan perilaku perawat. Tingkat 
keberhasilan dalam upaya pencegahan tergantung dari hal tersebut, akan tetapi berbagai studi mengindikasikan bahwa perawat tidak memiliki informasi dan pengetahuan yang cukup dalam memahami isi panduan penanganan dan kegiatan pencegahan dekubitus. ${ }^{6}$ Perawat merupakan petugas kesehatan yang bersama dengan pasien selama 24 jam, sehingga perawat memiliki peran penting dalam mencegah dekubitus. Adanya dekubitus berarti meningkatkan beban kerja perawat karena dekubitus membutuhkan pendekatan perawatan yang berbeda. $^{7}$ Dari hasil studi pendahuluan di salah satu rumah sakit di Yogya didapatkan data kejadian dekubitus pada tahun 2016 sebanyak 32 kasus dengan angka kejadian terbanyak di Bangsal Penyakit dalam yaitu 10 kasus. Angka kejadian dekubitus di rumah sakit di Yogya tergolong tinggi, oleh karena itu peneliti tertarik untuk melakukan penelitian tentang peran perawat dalam pencegahan dekubitus di bangsal penyakit dalam rumah sakit di Yogya. Tujuan penelitian ini adalah untuk mengetahui gambaran peran perawat dalam pencegahan dekubitus.

\section{BAHAN DAN CARA PENELITIAN}

Jenis penelitian ini penelitian kuantitatif dengan desain deskriptif menggunakan pendekatan waktu cross sectional. ${ }^{8}$ Populasi dalam penelitian ini adalah semua perawat yang bekerja di bangsal penyakit dalam rumah sakit di Yogya yang berjumlah 15 dan seluruh populasi dijadikan responden penelitian.

Variabel dalam penelitian ini adalah gambaran peran perawat dalam pencegahan dekubitus di bangsal penyakit dalam rumah sakit di Yogya berdasarkan kriteria perawat dan upaya dalam pencegahan dekubitus. Instrumen dalam penelitian ini adalah kuesioner peran perawat dalam pencegahan dekubitus terdiri atas 38 pernyataan yang dibuat oleh peneliti sesuai dengan konsep teori yang ada. Analisis data yang digunakan yaitu analisis deskriptif.

\section{HASIL DAN PEMBAHASAN \\ Karakteristik Responden}

Tabel 1. Karakteristik Perawat $(n=15)$

\begin{tabular}{llcc}
\hline \multicolumn{2}{c}{ Karakteristik } & F & $\%$ \\
\hline Jenis & Laki-laki & 2 & 13,3 \\
kelamin & Perempuan & 13 & 86,7 \\
\hline \multirow{2}{*}{ Usia } & Total & 15 & $100 \%$ \\
& $17-25$ tahun & 1 & 6,7 \\
& $26-35$ tahun & 12 & 80,0 \\
& $36-45$ tahun & 2 & 13,3 \\
\hline \multirow{2}{*}{ Lama kerja } & Total & 15 & $100 \%$ \\
& $\leq 3$ tahun & 6 & 40,0 \\
& $>3$ tahun & 9 & 60,0 \\
\hline Pendidikan & Total & 15 & $100 \%$ \\
& DIII & 13 & 86,7 \\
& S1/Ners & 2 & 13,3 \\
\hline & Total & 15 & $100 \%$
\end{tabular}

Sumber : data primer 2017

Hasil analisis Tabel 1. memperlihatkan bahwa sebagian besar responden berjenis kelamin perempuan. Menurut Firmansyah rerata jenis kelamin perawat pelaksana terbesar ialah perempuan $84,2 \%$ di mana perawat pelaksana berjenis kelamin perempuan lebih besar dibandingkan berjenis kelamin laki-laki, perempuan lebih cendrung memiliki caring karena sesuai dengan 
kodratnya sebagai seorang ibu, sehingga profesi perawat banyak diminati kaum perempuan, maka tidak mengherankan kalau proporsi perempuan lebih besar dibanding laki-laki. ${ }^{9}$ Rentang usia responden terbanyak yaitu 26-35 tahun atau masa dewasa awal. Masa dewasa awal secara psikologis telah mencapai perkembangan kognitif yang optimal sehingga memiliki kemampuan untuk menilai sesuatu secara objekif. ${ }^{10}$ Sebagian besar responden telah bekerja $>3$ tahun. Perawat dengan masa kerja lebih dari 3 tahun memiliki pengetahuan lebih baik dibandingkan perawat yang memiliki masa kerja kurang dari 3 tahun. ${ }^{11}$ Sebagian besar responden berpendidikan DIII Keperawatan. Bady menyatakan bahwa distribusi tingkat pendidikan formal tenaga keperawatan profesional hanya sebsar $6 \%$ yaitu tenaga keperawatan dengan pendidikan Sarjana Keperawatan atau S1, selebihnya tenaga keperawatan bukan profesional yaitu DIII/DIV $72 \%$ dan SPK/SPR $22 \% .^{12}$

\section{Peran Perawat dalam Pencegahan Dekubitus}

Tabel 2. Gambaran Peran Perawat dalam Pencegahan Dekubitus

\begin{tabular}{llcc}
\hline \multicolumn{1}{c}{ Variabel } & \multicolumn{1}{c}{ Kategori } & f & $\%$ \\
\hline Peran perawat & Baik $(\geq 89)$ & 10 & 66,7 \\
dalam & Cukup $(63-88)$ & 5 & 33,3 \\
$\begin{array}{l}\text { pencegahan } \\
\text { dekubitus }\end{array}$ & Kurang $(<63)$ & 0 & 0,0 \\
\hline & Total & 15 & 100 \\
\hline
\end{tabular}

Sumber : data primer 2017

Berdasarkan tabel 2. di atas diketahui bahwa sebagian besar perawat di Bangsal Penyakit dalam Rumah sakit di Yogya memiliki peran yang baik dalam pencegahan dekubitus 10 (66,7\%) dan 5 (33,3\%) perawat memiliki peran yang cukup dalam pencegahan dekubitus terutama pada domain memberikan support surface. Peran perawat dalam upaya pencegahan dekubitus merupakan prioritas dalam perawatan pasien dan tidak terbatas pada pasien imobilisasi saja. ${ }^{5}$ Hampir 95\% dekubitus dapat dicegah melalui tindakan keperawatan, sisanya $\leq 5 \%$ pasien imobilisasi tetap akan mengalami dekubitus. ${ }^{13}$ Peran perawat dalam pencegahan dekubitus terdiri atas 5 domain yang disajikan pada Tabel 3.

Tabel 3. Gambaran Peran Perawat Per Domain dalam Pencegahan Dekubitus

\begin{tabular}{|c|c|c|c|}
\hline Domain & Kategori & $\mathbf{F}$ & $\%$ \\
\hline Mengkaji & Baik $(\geq 14)$ & 9 & 60,0 \\
\hline \multirow[t]{2}{*}{ faktor risiko } & Cukup (10-13) & 6 & 40,0 \\
\hline & Total & 15 & 100 \\
\hline \multirow{3}{*}{$\begin{array}{l}\text { Perawatan } \\
\text { Kulit }\end{array}$} & Baik $(\geq 39,6)$ & 9 & \\
\hline & $\begin{array}{l}\text { Cukup } \\
39,5)\end{array}$ & $\begin{array}{l}y \\
6\end{array}$ & 40,0 \\
\hline & Total & 15 & 100 \\
\hline \multirow{3}{*}{$\begin{array}{l}\text { Memperbaiki } \\
\text { status nutrisi }\end{array}$} & Baik $(\geq 18,7)$ & 10 & 66,7 \\
\hline & $\begin{array}{l}\text { Cukup } \\
18,6)\end{array}$ & 5 & 33,3 \\
\hline & Total & 15 & 100 \\
\hline \multirow{3}{*}{$\begin{array}{l}\text { Support } \\
\text { Surface }\end{array}$} & Baik $(\geq 9,3)$ & 3 & 20,0 \\
\hline & $\begin{array}{l}\text { Cukup } \\
9,2)\end{array}$ & 12 & 80,0 \\
\hline & Total & 15 & 100 \\
\hline \multirow{3}{*}{ Edukasi } & Baik $(\geq 7)$ & 13 & 86,7 \\
\hline & Cukup $(5-6,9)$ & 2 & 13,3 \\
\hline & Total & 15 & 100 \\
\hline
\end{tabular}

Sumber : data primer 2017

Berdasarkan tabel 3. diketahui bahwa pada domain mengkaji faktor risiko dekubitus sebagian besar perawat memiliki peran yang baik 9 (60,0\%), dan 6 (40,0\%) perawat memiliki peran yang cukup dengan skor terendah $(1,5333)$ pada pernyataan mengkaji faktor risiko dekubitus menggunakan barthel 
index. Menurut Ropyanto, barthel index merupakan instrumen pengukuran status fungsional yang digunakan pada dewasa yang sedang dalam perawatan klinis maupun dalam area rehabilitasi dan bukan instrumen untuk mengkaji risiko dekubitus. ${ }^{14}$ Pada domain perawatan kulit sebagian besar perawat memiliki peran yang baik $9(60,0 \%)$ dan $6(40,0 \%)$ perawat memiliki peran yang cukup dengan skor terendah $(1,3333)$ pada pernyataan mengganti diapers pasien $1 \mathrm{x}$ sehari. Menurut penelitian Schindler, kejadian dekubitus di ruang perawatan anak mencapai $10,2 \%$ tetapi hal ini dapat dicegah dengan beberapa cara, jika pasien menggunakan diapers, maka gunakan diapers yang mempunyai daya serap tinggi dan pastikan diapers dalam keadaan kering, gunakan tempat tidur yang khusus, penuhi kebutuhan nutrisi, gunakan bantalan busa, gunakan body lotion, dan lakukan perubahan posisi setiap 2-4 jam. ${ }^{15}$ Pada domain memperbaiki status nutrisi sebagian besar perawat memiliki peran yang baik $10(66,7 \%)$, dan 5 $(33,3 \%)$ perawat memiliki peran yang cukup dengan skor terendah (1,5333) pada pernyataan memberikan makanan tinggi serat kepada pasien. Makanan tinggi serat bermanfaat untuk mengontrol berat badan, mencegah gangguan gastroinntestinal, mencegah kanker kolon, dan mengurangi tingkat kolesterol. ${ }^{16}$ Sedangkan untuk mencegah terjadinya dekubitus haruslah mengonsumsi makanan tinggi protein, minum air 6-8 gelas setiap hari, dan konsumsi kalori yang cukup untuk menjaga berat badan. ${ }^{17}$ Pada domain support surface sebagian besar perawat memiliki peran yang cukup 12 $(80,0 \%)$ dan hanya ada $3(20,0 \%)$ perawat yang memiliki peran yang baik, dengan skor terendah $(1,5333)$ pada pernyataan menggunakan kasur anti dekubitus sesuai orderan dokter, hal tersebut dikarenakan di Bangsal Penyakit dalam Rumah sakit di Yogya tidak mempunyai SOP pencegahan dekubitus sehingga perawat tidak melakukan tindakan pencegahan dekubitus dengan tepat. Perawat dapat mencegah dekubitus dengan memberikan support surface menggunakan pemakaian alat bantu khusus seperti kasur dekubitus, kursi dekubitus, dan bantal dekubitus karena dapat mencegah terjadinya pressure ulcer. ${ }^{18}$ Pada domain memberikan edukasi sebagian besar perawat memiliki peran yang baik $13(86,7 \%)$, dan 2 $(13,3 \%)$ perawat memiliki peran yang cukup dengan skor terendah $(2,5333)$ pada pernyataan melakukan demontrasi posisi yang tepat untuk mengurangi risiko dekubitus. Kurangnya pemberian pendidikan kesehatan oleh perawat dikarenakan perawat tidak memiliki informasi dan pengetahuan yang cukup dalam memahami isi panduan penanganan dan kegiatan pencegahan dekubitus. ${ }^{19}$

\section{Peran Perawat dalam Pencegahan Dekubitus berdasarkan Karakteristik Perawat}

Berdasarkan tabel 4. diketahui bahwa sebagian besar perawat perempuan di 
Bangsal Penyakit dalam Rumah sakit di Yogya mempunyai peran yang baik 10 $(76,9 \%)$ dan semua perawat laki-laki mempunyai peran yang cukup 2 (100,0 \%).

Tabel 4. Gambaran peran perawat dalam pencegahan dekubitus berdasarkan karakteristik

\begin{tabular}{|c|c|c|c|c|c|c|c|}
\hline \multirow{2}{*}{\multicolumn{2}{|c|}{ Karakteristik }} & \multicolumn{6}{|c|}{ Peran perawat } \\
\hline & & \multicolumn{2}{|c|}{ Baik } & \multicolumn{2}{|c|}{ Cukup } & \multicolumn{2}{|c|}{$\mathbf{N}$} \\
\hline & & f & $\%$ & $\mathbf{f}$ & $\%$ & $f$ & $\%$ \\
\hline \multirow{2}{*}{$\begin{array}{l}\text { Jenis } \\
\text { kelamin }\end{array}$} & Laki-laki & 0 & 0,0 & 2 & 100 & 2 & 100 \\
\hline & $\begin{array}{l}\text { Perempu } \\
\text { an }\end{array}$ & 10 & 76,9 & 3 & 23,1 & 13 & 100 \\
\hline \multirow[t]{3}{*}{ Umur } & $\begin{array}{l}17-25 \\
\text { tahun }\end{array}$ & 0 & 0,0 & 1 & 100 & 1 & 100 \\
\hline & $\begin{array}{l}26-35 \\
\text { tahun }\end{array}$ & 9 & 75,0 & 3 & 25,0 & 12 & 100 \\
\hline & $\begin{array}{l}36-45 \\
\text { tahun }\end{array}$ & 1 & 50,0 & 1 & 50,0 & 2 & 100 \\
\hline \multirow{2}{*}{$\begin{array}{l}\text { Lama } \\
\text { Kerja }\end{array}$} & Baru & 4 & 66,7 & 2 & 33,3 & 6 & 100 \\
\hline & Lama & 6 & 66,7 & 3 & 33,3 & 9 & 100 \\
\hline \multirow{2}{*}{$\begin{array}{l}\text { Pendidik } \\
\text { an }\end{array}$} & DIII & 8 & 61,5 & 5 & 38,5 & 13 & 100 \\
\hline & S1/Ners & 2 & 100 & 0 & 0,0 & 2 & 100 \\
\hline
\end{tabular}

Sumber : data primer 2017

Jenis kelamin berkorelasi positif terhadap kinerja, perawat perempuan cenderung mempunyai kinerja lebih baik dibanding dengan pria dalam memberikan asuhan keperawatan pada pasien. ${ }^{20}$ Dilihat dari rentang usia perawat, sebagian besar perawat dengan rentang usia 26-35 tahun mempunyai peran yang baik 9 (75,0 \%). Hal ini sejalan dengan penelitian di Rumah Sakit Amman, Yordania, di mana hasil penelitiannya menunjukkan bahwa usia sebagian besar perawat yang mempunyai tingkat pengetahuan yang baik terhadap pencegahan luka dekubitus adalah 26-30 tahun. ${ }^{21}$ Dilihat dari lama kerja, sebagian besar perawat dengan masa kerja $>3$ tahun mempunyai peran yang baik $6(66,7 \%)$.
Perawat dengan masa kerja yang lama cenderung melakukan pendokumentasian dengan baik, semakin lama seseorang bekerja, kecakapan akan semakin baik karena dapat menyesuaikan diri dengan pekerjaannya dan seseorang akan mencapai kepuasan tertentu bila sudah mampu menyesuaikan diri dengan lingkungan. ${ }^{22}$ Dilihat dari tingkat pendidikan, sebagian besar perawat mempunyai tingkat pendidikan DIII dan mempunyai peran yang baik 8 $(61,5 \%)$ dan semua perawat dengan tingkat pendidikan S-1 atau Ners seluruhnya mempunyai peran yang baik 2 (100,0 \%). Pendidikan memberikan pengetahuan sebagai landasan untuk mengembangkan diri serta kemampuan memanfaatkan semua sarana untuk kelancaran tugas. Tenaga keperawatan yang berpendidikan tinggi motivasinya akan lebih baik karena telah memiliki pengetahuan dan wawasan yang lebih luas. ${ }^{23}$

\section{KESIMPULAN}

Berdasarkan dari uraian hasil penelitian dan pembahasan tentang peran perawat dalam pencegahan dekubitus di bangsal penyakit dalam rumah sakit di Yogya, dapat disimpulkan bahwa karaktersitik perawat di bangsal penyakit dalam mayoritas adalah perempuan yaitu $13(86,7 \%)$ dengan rentang usia 26-35 tahun yaitu 12 (80,0\%), telah bekerja > 3 tahun yaitu 9 (60,0\%), dan mayoritas pendidikan perawat adalah DIII yaitu $13(86,7 \%)$. Sebagian besar perawat di 
Bangsal Penyakit dalam Rumah sakit di Yogya memiliki peran yang baik dalam pencegahan dekubitus 10 (66,7\%). Peran perawat dalam pengkajian faktor risiko dekubitus dalam kategori baik 9 (60,0\%), tetapi diharapkan agar perawat menggunakan instrumen yang tepat untuk mengkaji risiko dekubitus . Peran perawat dalam perawatan kulit pasien dalam kategori baik 9 (60,0\%), tetapi diharapkan perawat agar selalu menjaga kebersihan dan kelembaban kulit pasien dari cairan tubuh. Peran perawat dalam memperbaiki status nutrisi pasien dalam kategori baik 10 $(66,7 \%)$, tetapi diharapkan agar perawat memenuhi kebutuhan nutrisi pasien dengan memberikan makanan tinggi protein. Peran perawat dalam support surface terhadap pasien dalam kategori cukup 12 (80,0\%), untuk meningkatkan peran perawat dalam support surface diharapkan agar pihak manajemen rumah sakit menyediakan SOP pencegahan dekubitus agar perawat dapat melakukan pencegahan dekubitus sesuai dengan SOP yang berlaku. Peran perawat dalam memberikan edukasi pasien dalam kategori baik $13(86,7 \%)$, tetapi diharapkan agar perawat melakukan pendidikan kesehatan pencegahan dekubitus secara rutin kepada keluarga dan pasien.

\section{TERIMA KASIH}

Kuswanto Hardjo, dr., M.Kes selaku Dekan Fakultas Kesehatan Universitas Jenderal Achmad Yani Yogyakarta.

\section{KEPUSTAKAAN}

1. Martini, D. Asiandi, Handayani, D.Y. (2012). The Impact of the Lying Change in Protecting the Risk of Dekubitus on the Stroke Patients at RSUD Banyumas. J urnal Keperawatan. Vol 11. Hal 413-799.

2. Suriadi, Sanada, H., Sugama, J., Thigpen, B., dan Subuh, M. (2007). Risk Factors In The Development Of Pressure Ulcers In An Intensive Care Unit In Pontianak, Indonesia. International Wound Journal. Vol 4, issue 3. Hal $208-215$. Diakses dari www.ncbi.nlm.nih.gov/pubmed/1792877 pada tanggal 14 Maret 2017.

3. WHO. (2002). Pedoman Perawatan Pasien. Alih bahasa, Monica Ester. Editor, Esty W., \& Nike B.S., Jakarta: EGC

4. Mukti, E.N. (2006). Penelusuran Hasil Penelitian Tentang Intervensi Keperawatan Dalam Pencegahan Luka Dekubitus pada Orang Dewasa. Jurnal Keperawatan Indonesia. Vol 1, No 3.

5. Potter \& Perry. (2006). Fundamental of Nursing: Fundamental Keperawatan (Ed.7). Jakarta : Salemba Medik.

6. Buss, (2009). Pressure Ulcer Prevention In Nursing Home: Views And Beliefes Of Enrolled Nurse And Other Health Workers. J ournal of Clinical Nursing. Vol 13. Hal 668-676. Diakses dari www.ncbi.nlm.nih.gov/pubmed/15317506 pada tanggal 20 Maret 2017.

7. Kallman, U. \& Suserud, B-Oasa. (2009). Knowledge, Attitudes And Practice Among Nursing Staff Concerning Pressure Ulcer Prevention And Treatment - A Survey In A Swedish Healthcare Setting. J ournal Compilation. Nordic College of Caring Science. Diakses dari www.ncbi.nih.gov/pubmed/19645807 pada tanggal 15 Februari 2017.

8. Notoadmodjo, S. (2012). Metodologi Penelitian Kesehatan. Jakarta : Rineka Cipta.

9. Firmansyah, M. (2009). 'Pengaruh Karakteristik Organisasi Terhadap Kinerja Perawat dalam Melaksanakan Asuhan Keperawatan Untuk Membantu Promosi Kesehatan di Rumah Sakit Umum Sigli'. Tesis. Sekolah Pascasarjana Universitas Sumatera Utara. Diakses dari www.repository.usu.ac.id/bitstream/handle 
/123456789/6891/10E00582.pdf;jsessionid $=21 \mathrm{C} 063 \mathrm{CBE} 16 \mathrm{C} 5 \mathrm{BA5419F2C4FAAD046}$ $4 \mathrm{C}$ ? sequence $=1$ pada tanggal 10 Agustus 2017.

10. Potter \& Perry. (2011). Basic Nursing. Edisi 7. St. Louis : Mosby Elsevier.

11. Sofiana, N.A., dan Purbadi, D. (2006). 'Analisis Faktor Lingkungan dan Individu yang Berpengaruh Terhadap Peningkatan Kinerja Perawat'. Tesis. Institut Teknologi Bandung. Diakses dari http://digilib.itb.ac.id/dgl.php?mod=browse \&op=read\&id=jbptsbmitb-dgl-nooraridas86 pada tanggal 3 Agustus 2017.

12. Bady, A.M., Kusnanto, H., dan Handono, D. (2007). 'Analisis Kinerja Perawat Dalam Pengendalian Infeksi Nosokomial di Irna RSUP Dr Sardjito'. Distant Learning Resouce Center KMPK Universitas Gadjah Mada. Working Paper Series. No 8. Hal 1-10. Diakses dari www.infodiknas.com/wpcontent/uploads/2 014/11/ANALISISKINERJAPERAWATDAL AMPENGENDALIANINFEKSINOSOKOMI AL-DI-IRNA-I-RSUP-DR.-SARDJITO.pdf pada tanggal 17 Agustus 2017.

13. The Agency for Health Care Policy and Research, 2009. Panel on the Prediction and Prevention of Pressure Ulcers in Adults. Diakses dari www.ahrq.gov/professionals/systems/hosp ital/pressureulcertoolkit/putool3a.html pada tanggal 1 Agustus 2017.

14. Ropyanto, C.B. (2011). 'Analisis FaktorFaktor Yang Berhubungan Dengan Status Fungsional Pasien Paska Open Reduction (Orif) Fraktur Ekstremitas Bawah Di RS. Ortopedi Prof. Soeharso Surakarta'. Tesis. Magister IImu Keperawatan. Universitas Indonesia. Diakses dari www.lib.ui.ac.id/file?file=digital/20281386T \%20Chandra\%20Bagus\%20Ropyanto.pdf pada tanggal 3 Agustus 2017.

15. Schindler, C.A., Mikhailov, T.A., Khun, E.M., Christoper, J., Conway, P., Ridling, D., dkk. (2011). Protecting Fragile Skin: Nursing Interventions to Decrease Development of Pressure Ulcers in Pediatric Intensive Care. National Librarry of Medicine National Institutes of Health. Vol 20, No. 1. Hal 26-34. Diakses dari www.ncbi.nlm.nih.gov/pubmed/21196569 pada 3 Agustus 2017.

16. Herminingsih, A. (2010). Manfaat Serat dalam Menu Makanan. Universitas Mercu Buana, Jakarta.

17. Koller, K., dan Price, S. (2015). Nutrition for Preventing and Treating Pressure Ulcer. University of Michigan Health System : Creative Commons AttributionNonCommercial-ShareAlike 3.0 Unported License. Diakses dari www.med.umich.edu/1libr/Nutrition/DietPr essureUlcers.pdf pada tanggal 3 Agustus 2017.

18. National Safety and Quality Health Service Standars. (2012). Preventing and Managing P ressure Injury. Second edition. Hal 54-60. Australian Commission Safety And Quality In Health Care. Sydney Australia. Diakses dari www.safetyandquality.gov.au/wpcontent/uploads/2011/09/NSQHS-

Standards-Sept-2012.pdf pada tanggal 3 Agustus 2017.

19. Setiyawan. (2008). 'Hubungan Tingkat Pengetahuan Dan Sikap Dengan Perilaku Perawat Dalam Upaya Pencegahan Dekubitus Di Rumah Sakit Cakra Husada Klaten'. Skripsi. Sarjana Keperawatan. STIKES Kusuma Husada Surakarta. Diakses dari www.jurnal.stikeskusumahusada.ac.id/ind ex pada tanggal 20 Februari 2017.

20. Al-Ahmadi, H. (2009). Factor Affecting Performance of Hospital Nurses in Riyadh Region. Saudi Arabia: International J ournal of Health Care Quality Assurance. Vol 22. Issue 1. Hal 40-54. Diakses dari www.ncbi.nlm.nih.gov/pubmed/19284170 pada tanggal 3 Agustus 2017.

21. Qaddumi, J., \& Khawaldeh, A. (2014). Pressure Ulcer Prevention Knowledge Among Jordanian Nurses: A CrossSectional Study. BMC Nursing. Vol 13, No $6 . \quad$ Diakses dari www.ncbi.nlm.nih.gov/pmc/articles/PMC39 46597/ pada tanggal 3 Agustus 2017.

22. Al Kharabsheh, M., Alrimawi, R., Al Assaf, R., dan Saleh, M. (2014). Exploring Nurses' Knowledge and Perceived Barriers to Carry Out Pressure Ulcer Prevention and Treatment, 
Documentation, and Risk Assessment. American International Journal of Contemporary Research, Vol 4, No 4. Hal 112 - 119. Diakses dari www.aijcrnet.com/journals/Vol_4_No_4_A pril_2014/15.pdf pada tanggal 3 Agustus 2017.
23. Kumajas, F.W., Warouw, H., dan Bawatong, J. (2014). Hubungan Karakteristik Individu dengan Kinerja Perawat di Ruang Rawat Inap Penyakit Dalam RSUD Datoe Binangkang Kabupaten Bolang Mongondow. Jurnal Keperawatan Universitas Sam Ratulangi. Vol 2, No 2. Hal 1-8 